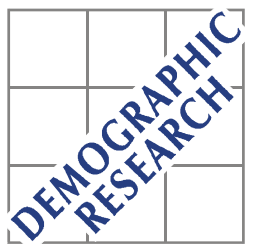

Demographic Research a free, expedited, online journal of peer-reviewed research and commentary in the population sciences published by the Max Planck Institute for Demographic Research Konrad-Zuse Str. 1, D-18057 Rostock · GERMANY www.demographic-research.org

DEMOGRAPHIC RESEARCH

VOLUME 9, ARTICLE 6, PAGES 111-118

PUBLISHED 15 OCTOBER 2003

www.demographic-research.org/Volumes/Vol9/6/

DOI: 10.4054/DemRes.2003.9.6

Research Article

\title{
A diminishing population whose every cohort more than replaces itself
}

Robert Schoen

Stefan H. Jonsson

(C) 2003 Max-Planck-Gesellschaft. 


\section{Table of Contents}

1 Introduction 112

2 The period/cohort paradox 112

3 Resolving the paradox 113

$4 \quad$ Some numerical illustrations $\quad 114$

5 Conclusion 116

$\begin{array}{ll}\text { Notes } & 117\end{array}$

$\begin{array}{ll}\text { References } & 118\end{array}$ 
Research Article

\title{
A diminishing population whose every cohort more than replaces itself
}

\author{
Robert Schoen ${ }^{1}$ \\ Stefan Hrafn Jonsson ${ }^{2}$
}

\begin{abstract}
We observe that a dynamic population model can have period fertility that is always below replacement and cohort fertility that is always above replacement. We ask whether such a paradoxical population will get larger or smaller, and show that it must become smaller. Cohort replacement does not imply population replacement, and emphasizing fertility timing and cohort fertility ignores the issue of relative cohort size. The resolution of this apparent paradox reinforces the importance of the level of period fertility in demographic analysis.
\end{abstract}




\section{Introduction}

Comparisons of the period and cohort perspectives on fertility have a long history in demography (e.g. Ryder 1980; Ni Bhrolchain 1992). In a paper "On the Quantum and Tempo of Fertility", Bongaarts and Feeney (1998) extended that line of research and introduced a new and intriguing dynamic (i.e. changing rate) population model. In their "Scenario 2", they assumed a specified age-specific fertility rate schedule, where initially (at time 0) childbearing begins at age $\alpha$ and ends at age $\beta$. They then examined the situation where every year the fertility schedule, while maintaining its original shape, moves along the age axis by a given amount (say c years). Thus at time 1, childbearing begins at age $\alpha+c$ and ends at $\beta+c$; at time 2, childbearing begins at $\alpha+2 c$ and ends at $\beta+2 c$; and so on. Consider a population in which such a pattern of change has been in place for at least $\beta$ years. Bongaarts and Feeney (1998) showed that if the fixed period Total Fertility Rate (TFR) implied by the constant (though shifting) fertility schedule is $\mathrm{TFR}_{\mathrm{p}}$, then the population's cohort Total Fertility Rate (CFR) has a constant value given by

$$
\mathrm{CFR}=\mathrm{TFR}_{\mathrm{p}} /(1-\mathrm{c})
$$

Thus if, in every period, the population has a TFR of 1.4 while the fertility schedule is increasing by .2 years every year, then every cohort in that population has a CFR of 1.4/0.8 or 1.75. While the relationship in equation (1) generally does not extend to other patterns of fertility change, Kim and Schoen (2000) confirmed it for the circumstances described above. ${ }^{1}$

\section{The period/cohort paradox}

The relationship between period and cohort fertility in the Bongaarts-Feeney model described above can lead to an apparent paradox. For simplicity ${ }^{2}$, let us only consider female births, and assume that there is no mortality before the highest age at childbearing. If, on average, every woman has one daughter, that yields a Net Reproduction Rate (NRR) of 1.0 and a population that just replaces itself. Now consider the situation where the period fertility schedule implies that, on average, every woman has 0.9 daughters, but where that fertility schedule (and thus the mean age at childbearing) advances by 0.2 years every year. In that case, the period NRR (i.e. $\mathrm{NRR}_{\mathrm{p}}$ ) would be 0.9 , below replacement level. However, the NRR of every cohort (i.e. CRR) would be $0.9 / 0.8$ or 1.125 , which is clearly above replacement level. Thus we either have a population that is growing in size despite the fact that every year it has an NRR of less than 1, or we have a population that is diminishing in size although every cohort more than replaces itself. 


\section{Resolving the paradox}

Some reflection shows that the population must be declining in size. To analyze the dynamics, think of a "rectangular" population that has 1 person at every age through the highest age of reproduction. Such a population would be maintained if $N_{R R}$ were 1 . Now assume that, at time 0 , fertility declines proportionately at all ages to yield a $\mathrm{NRR}_{\mathrm{p}}$ of 0.9 , while the fertility schedule starts to increase (i.e. move to higher ages) by 0.2 years each year. The next year, there would be only 0.9 births, and births would remain at that level until enough time passes for those smaller cohorts to begin childbearing. At that point, the number of births would decline even further. Thus starting with a zero growth population leads to a diminishing birth sequence, regardless of how much the fertility schedule shifts each year. Having a time 0 population where the number of persons was declining with age would only accelerate the decline in birth cohort size just described.

It should be noted that this argument is not limited to the Bongaarts-Feeney pattern of change. It applies to all situations where an initial rectangular population experiences a series of period fertility rates that are below replacement level (as long as there is nonzero fertility at every age during the reproductive age interval). For example, if the period NRR is fixed at 0.9 , as in the above case, there can never be more than 0.9 births in a year regardless of how the timing of fertility changes, and the number of births must decline over time. ${ }^{3}$

Under the Bongaarts-Feeney scenario, our diminishing population is the product of a sequence of changing age-specific birth rates, and its composition at any point in time differs from that of the stable population implied by the vital rates of that time. Comparing the two populations provides a different perspective on the nature of the dynamic population. One can deduce that at any time $t$ the dynamic population is decreasing at a rate slower (i.e. less negative) than that of the stable population implied by the rates at time t. To see that, assume that the composition of the population at time $t$ is that of the stable population implied by time $t$ rates. The stable rate of growth must be negative here, because period fertility is below replacement. Accordingly, in the absence of mortality below the highest age at reproduction, the number of persons in the stable population increases with age through the reproductive years. A shift in the fertility schedule to a higher age would thus cause an increase in the number of births, with the amount of that increase greater for a larger upward shift. Since the number of births in the stable population is declining over time, such an increase is inconsistent with the premise of a stable age composition. Instead it indicates that the number of persons in our dynamic population is increasing more slowly with age, and hence the dynamic population has been declining at a rate that is less negative than the stable rate. In short, a pattern of later ages at childbearing slows, but does not stop, the rate of decline in the number of births. 


\section{Some numerical illustrations}

Figure 1 shows the annual number of births in 4 hypothetical populations representing the combination of 2 values of $\mathrm{NRR}_{\mathrm{p}}(.990$ and .975$)$ and 2 values of $\mathrm{c}(.03$ and .05$)$. All 4 combinations produce the period/cohort paradox situation. In addition, the number of births when $\mathrm{c}=0$ is shown (i.e. the number of births in the stable population implied by the $\mathrm{NRR}_{\mathrm{p}}$ ). In every case, the calculations ${ }^{4}$ assumed a rectangular population at time 0 . Figure 1 shows values beginning at time 150 , when the effects of the time 0 population composition on the birth sequence have largely disappeared.

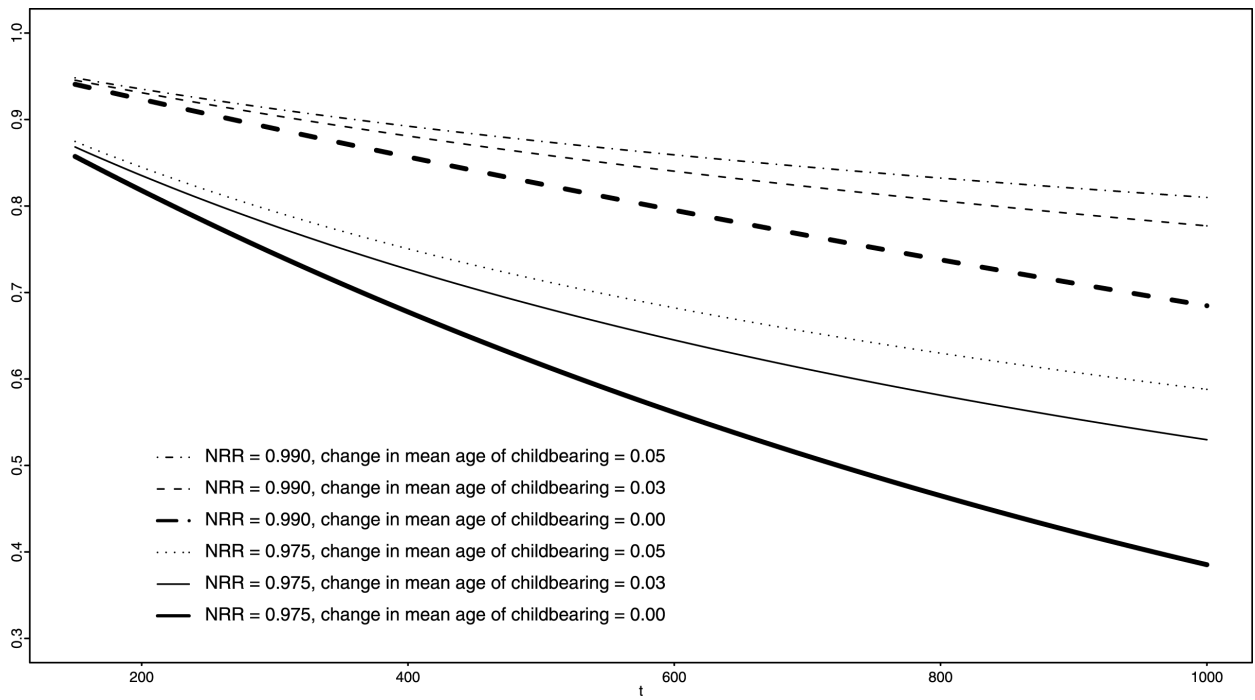

Figure 1: Annual number of births in the model by NRR and annual change in the mean age of childbearing

Figure 1 clearly indicates that in every case the number of births declines over time. The drop in $\mathrm{NRR}_{\mathrm{p}}$ has a greater impact on the rate of decline than the drop in $\mathrm{c}$, but a smaller annual increase in the mean age of childbearing also leads to a faster rate of decline in number of births. For each $\mathrm{NRR}_{\mathrm{p}}$, the decline in the number of births is greatest when $\mathrm{c}=0$. As Figure 1 shows, these declines can continue for centuries under plausible demographic conditions. For example, with $\mathrm{c}=.03$, the childbearing ages shift upwards by only 15 years after 500 years of time have elapsed. 
Figure 2 compares the proportional decline in the annual number of births in our dynamic population with that in the stable population having the same vital rates at that point in time. The same 4 combinations of $N_{R R}$ and $c$ are examined. Although values again start at time 150 , some fluctuations in the rate of decline stemming from the initial population composition are still present.
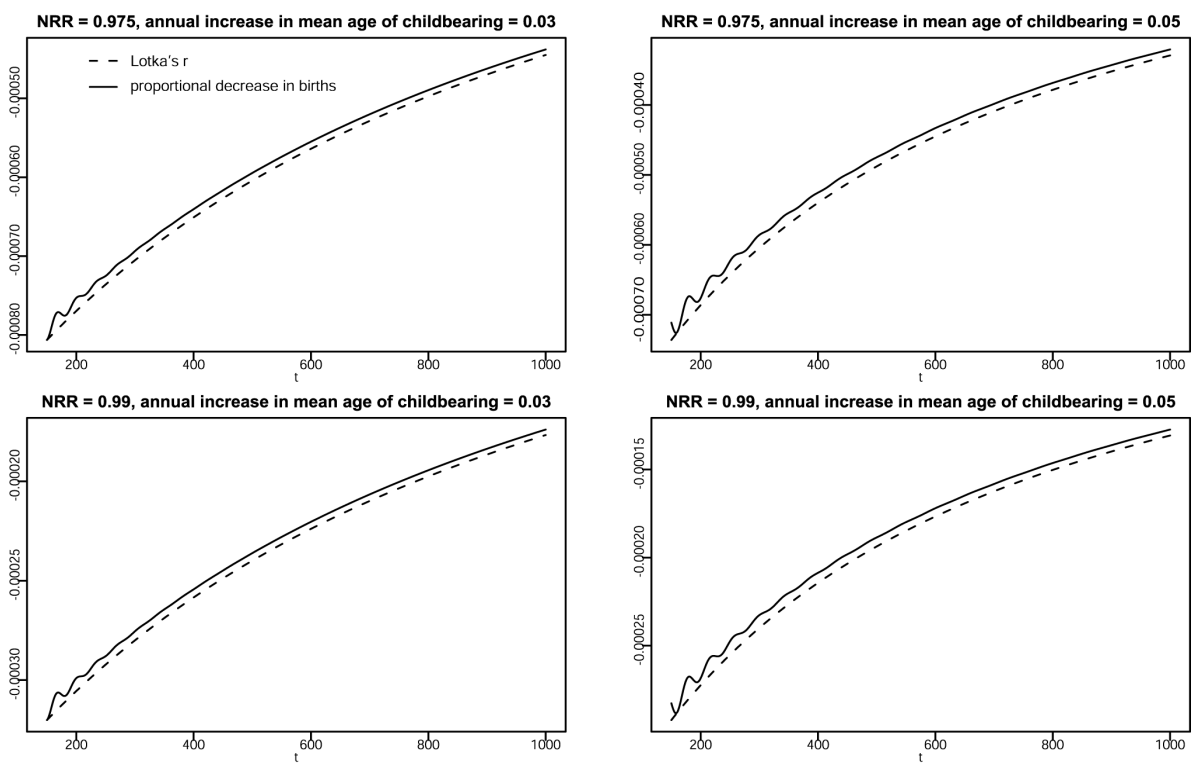

Figure 2: $\quad L o t k a$ 's $r$ and the proportional decline in annual number of births by NRR and annual change in the mean age of childbearing

Figure 2 confirms that the dynamic population has a slower (i.e. smaller negative) rate of decline in the annual number of births than does its associated stable population. That pattern holds for all 4 populations considered, though the difference between the rates of decline is modest. Both dynamic and associated stable populations have the same pattern of change over time, with the rate of decline in the birth sequence becoming a smaller negative value over time. As the number of births approaches 0 , the rate of decline also approaches zero. 


\section{Conclusion}

Dynamic models can yield relationships that are not possible in fixed rate models. Here we see that the Bongaarts-Feeney dynamic fertility model can lead to a population with period fertility consistently below replacement and cohort fertility consistently above replacement. Our analysis resolves that apparent paradox by showing that constant annual increases in the mean age at childbearing slow, but do not prevent, a decrease in population size when period fertility is below replacement. ${ }^{5}$

Intuitively, how is such a pattern possible? The short answer is that cohort size is steadily declining over time. In any year, the number of births is determined by period fertility and population composition (i.e. the number of survivors from births of previous years). If period fertility stays below replacement, birth cohort size must eventually decline. Nothing in the timing of fertility can prevent that from happening.

Period fertility thus plays a unique role that should not be obscured by a focus on cohort fertility or on the timing of childbearing. In the model examined here, timing considerations and an emphasis on completed family size would be fundamentally misleading with respect to the evolution of population size, because neither considers cohort size. A timing induced increase in cohort fertility can lead to cohort replacement but not population replacement. That point is worth remembering in the contemporary situation, where many developed countries have below replacement fertility and a recent history of rising ages at childbearing (cf. Lutz, O’Neill, and Scherbov 2003). Period may or may not be paramount in fertility analysis (cf. Ni Bhrolchain1992), but it is definitely indispensable to understanding the role of fertility in population change. 


\section{Notes}

1. Bongaarts and Feeney (1998), which focused on adjusting observed period fertility to reflect changes in fertility timing, stimulated a strong and continuing response. In addition to Kim and Schoen (2000), notable work includes Bongaarts and Feeney (2000), Kohler and Philipov (2001), Lesthaeghe and Willems (1999), Van Imhoff and Keilman (2000), and Zeng and Land (2002).

2. As has been noted elsewhere, the Bongaarts-Feeney pattern of fertility change is rather unrealistic, and a continuing increase in the ages of reproduction would inevitably lead to women bearing children at what are now considered absurdly high ages. The model can be made more palatable for a longer period of time by reframing it in terms of male fertility behavior during a sustained period of delayed marriage and improving health. Moreover, if the annual increase in the fertility schedule is small, the pattern could continue for many years, even centuries, without yielding absurd values.

3. In the very long term, the birth trajectory of a demographically realistic changing rate population whose cohort TFR is greater than 1 but whose period TFR is not specified appears to be indeterminate. If the cohort rates become constant over time, the period TFR becomes constant at a level above 1 and an increasing stable population results. Alternatively, the cohort fertility schedule could abruptly shift to much younger ages, and then begin to move upwards again. In that case, one might see a temporary rise followed by a resumption of the decline in the number of births. The complex dynamics of changing rate populations have not been studied in depth, though Kim and Sykes (1978) identified some of the indeterminate and counterintuitive results that can arise even when the NRR $=1$ and there are only two age groups.

4. The single year age-specific fertility pattern used is that attributed to the United States in 1999 in the middle series of the 1999 to 2100 Census Bureau population projection (U.S. Census Bureau 2002).

5. If $\mathrm{NRR}_{\mathrm{p}}$ is above replacement but the fertility schedule steadily shifts to younger ages, the reverse of the paradox examined here would result. Period fertility would again govern, and the number of births would steadily increase. Under this reversed scenario, one would have cohorts of ever larger size failing to replace themselves. 


\section{References}

Bongaarts, J. and G. Feeney. 1998. "On the Quantum and Tempo of Fertility," Population and Development Review 24: 271-91.

Bongaarts, J. and G. Feeney. 2000. "On the Quantum and Tempo of Fertility: Reply," Population and Development Review 26: 560-64.

Kim, Y.J. and R. Schoen. 2000. "On the Quantum and Tempo of Fertility: Limits to the Bongaarts-Feeney Adjustment," Population and Development Review 26: 554-59.

Kim, Y.J. and Z.M. Sykes. 1978. "Dynamics of some special populations with NRR=1," Demography 15: 559-69.

Kohler, H.P. and D. Philipov. 2001. "Variance Effects in the Bongaarts-Feeney Formula," Demography 38: 1-16.

Lesthaeghe, R. and P. Willems. 1999. "Is Low Fertility a Temporary Phenomenon in the European Union?" Population and Development Review 25: 211-28.

Lutz, W., B.C. O’Neill, and S. Scherbov. 2003. "Europe's population at a turning point." Science 299(28 March): 1991-92.

Ni Bhrolchain, M. 1992. "Period paramount? A Critique of the Cohort Approach to Fertility," Population and Development Review 18: 599-629.

Ryder, N.B. 1980. "Components of temporal variations in American fertility." Pp. 15-54 in R.W. Hiorns (ed) Demographic Patterns in Developed Societies. London: Taylor and Francis.

U.S. Census Bureau. 2002. Population Projections of the United States by Age, Sex, Race, Hispanic Origin, and Nativity: 1999 to 2100. Taken from http://www.census.gov/population/projections.

Van Imhoff, E. and N. Keilman. 2000. "On the Quantum and Tempo of Fertility: Comment," Population and Development Review 26: 549-53.

Zeng, Y. and K.C. Land. 2002. "Adjusting Period Tempo Changes With an Extension of Ryder's Basic Translation Equation," Demography 39: 269-85. 